\title{
Axial Dispersion and Mass Transfer of a Pulsed Solvent Extraction Column with Novel Ceramic Internals
} Heng Yi ${ }^{a, b}$, Yong Wang ${ }^{b}$, Kathryn H. Smith ${ }^{b}$, Weiyang Fei ${ }^{a,{ }^{*}}$ and Geoffrey W. Stevens ${ }^{b, *}$

${ }^{a}$ Department of Chemical Engineering, Tsinghua University, Beijing, 100084, China

${ }^{b}$ Department of Chemical and Biomolecular Engineering, The University of Melbourne, Parkville, Victoria 3010, Australia

ABSTRACT: Two types of novel anti-corrosive ceramic internals, the hybrid ceramic internal and ceramic plate, are designed and tested under pilot conditions for future industrial application in lithium extraction from salt lake brine. A standard liquid-liquid system with medium interfacial tension, 30\% TBP in Shellsol 2046-water with acetic acid as solute, is used to test axial dispersion and mass transfer parameters, which are important to determine height of extraction columns, over a range of operating conditions. Results show that the hybrid ceramic internal has 50\% lower axial dispersion coefficient and $50 \%$ higher mass transfer coefficient, both contributing to better mass transfer performance. Under proper operating condition, height of transfer unit of hybrid ceramic internal can reach as low as around $0.2 \mathrm{~m}$, which shows very good efficiency and makes it promising to be applied in the near future.

\section{Key words:}

Solvent extraction column, Ceramic internal, Axial dispersion, Mass transfer 


\section{Introduction}

Liquid-liquid extraction is an important separation process. An extraction column has

advantages such as high volume efficiency, small footprint and environmentally friendly

features over other solvent extraction contacting devices, so they have been used for a range of applications in chemical, petroleum, nuclear, hydrometallurgical and other industries for many years ${ }^{1-3}$. Among the different types of extraction columns, the pulsed sieve plate column is characterized by the absence of moving mechanical parts which avoids frequent maintenance and the mode of providing energy which makes remote operation possible ${ }^{4,5}$. Because of these advantages, pulsed sieve plate columns are widely applied especially in the nuclear fuel reprocessing field ${ }^{6,7}$.

Researchers have made efforts to investigate the performance of pulsed sieve plate columns for decades. Yadav et al. ${ }^{8}$ gave a thorough summary of previous work and a comparison of different correlations about design aspects of pulsed sieve plate column including drop size, holdup, flooding point and mass transfer, among which the first three can be classified into hydrodynamic parameters. Hydrodynamic parameters are important to determine the column throughput, while mass transfer is the key parameter to determine separation efficiency ${ }^{9,10}$. Recent studies have investigated hydrodynamic ${ }^{11-14}$ and mass transfer performance ${ }^{13,15,16}$ of pulsed sieve plate columns. According to Yadav et al. ${ }^{8}$, many researchers interpret the mass transfer data without taking into account the effect of axial dispersion, which according to Nabli et al. ${ }^{17}$ would cause over-prediction of the separation efficiency by up to $30 \%$. Therefore the ability to predict axial dispersion coefficients is necessary to better understand the mass transfer process in an extraction column. 
Researchers are still making efforts to develop better ways to investigate axial dispersion in pulsed sieve plate columns $s^{5,18,19}$

Extraction of lithium from chloride brine in salt lakes is a separation process of great importance ${ }^{20}$. It is also a promising industrial field where solvent extraction columns are likely to be used, since efforts have been made to apply pulsed sieve plate columns in another hydrometallurgy application of copper extraction ${ }^{21,22}$. However the extraction solution is corrosive to traditional stainless steel column internals because of their high chloride content, thus the development of novel anti-corrosive internals is necessary.

Therefore two types of novel ceramic internals, the ceramic plate and the hybrid ceramic internal have been designed and manufactured. Ceramic plate is designed based on standard sieve plate, while hybrid ceramic internal is designed by adding ceramic packing on ceramic plate. This design is likely to intensify mass transfer by reinforcing breakage-coalescence cycle for dispersed droplets along the column.

Because the difference in wettability resulted from material types will effect performance of pulsed sieve plate columns ${ }^{23,24}$, it's necessary to evaluate the novel ceramic plate and hybrid ceramic internal under pilot plant conditions before industrial applications. The hydrodynamic results including holdup, characteristic velocity and drop size for these two types of ceramic internals have been reported by Yi et $\mathrm{al}^{25}$. The focus of the current study is to investigate the mass transfer performance of these novel ceramic internals. A prior investigation is conducted to provide information about axial dispersion coefficients, in order for a better interpretation of mass transfer data and a better explanation of the performance comparison between these two types of internals. 


\section{Previous studies}

\subsection{Axial dispersion}

In the axial dispersion model for solvent extraction columns, deviation caused by non-ideality from plug flow is taken into account via an axial dispersion coefficient for each phase ${ }^{26}$, which makes it an important design parameter for determining the height of an extraction column for a given separation. The effect of axial dispersion in the dispersed phase is usually regarded as negligible for pulsed columns ${ }^{27}$, thus most attention is paid to axial dispersion in the continuous phase. Axial dispersion in the continuous phase has been studied by researchers in various types of liquid-liquid extraction columns, such as pulsed sieve plate extraction columns ${ }^{19,28,29}$, reciprocating plate extraction columns $\mathrm{s}^{30,31}$ and spray towers ${ }^{32}$.

$$
\text { In order to predict the extent of axial dispersion, various correlations for the axial }
$$

dispersion coefficient, $E_{c}$, have been proposed. In some of these studies, the correlations were based on limited experimental data and therefore are only applicable to the specific situations and operating variables for which the correlation was developed. An example is given in Equation 1 by Kagan et al..$^{33}$ for two-phase operation of a pulsed sieve plate column:

$$
E_{c}\left(1-x_{d}\right)=1.26 \times 10^{-4} A^{1.2} f^{1.35} /\left(V_{c}+V_{d}\right)^{1.4}
$$

Later Tung and Luecke $^{34}$ made an effort to develop a more generalized correlation for $E_{c}$ with published data for pulsed sieve plate columns, which takes into account the effect of column geometries. A similar correlation (shown in Equation 2) proposed by Srinikethan 
et al. ${ }^{35}$ further takes into account the effect of pulsation rate (Af) and continuous phase velocity $\left(\mathrm{V}_{\mathrm{c}}\right)$ on $\mathrm{E}_{\mathrm{c}}$ separately via different number groups:

$$
\frac{\mathrm{E}_{\mathrm{c}}}{\mathrm{h}_{\mathrm{c}} \mathrm{V}_{\mathrm{c}}}=\mathrm{k}_{1}\left(\frac{\mathrm{Af}}{\mathrm{V}_{\mathrm{c}}}\right)^{\mathrm{k}_{2}}\left(\frac{\mu_{\mathrm{c}}}{\mathrm{V}_{\mathrm{c}} \mathrm{d}_{0} \rho_{\mathrm{c}}}\right)^{\mathrm{k}_{3}}\left(\frac{\mathrm{d}_{0}}{\mathrm{~h}_{\mathrm{c}}}\right)^{\mathrm{k}_{4}} \alpha^{\mathrm{k}_{5}}
$$

where $\mathrm{k}_{1}=3.65, \mathrm{k}_{2}=0.3, \mathrm{k}_{3}=0.2, \mathrm{k}_{4}=0.45, \mathrm{k}_{5}=-0.22$ for the mixer-settler region, and $\mathrm{k}_{1}=3.25, \mathrm{k}_{2}=0.3, \mathrm{k}_{3}=0.2, \mathrm{k}_{4}=0.8, \mathrm{k}_{5}=-0.8$ for the emulsion region.

\section{Later Kumar and Hartland ${ }^{28}$ collected 992 data points with and without mass transfer}

for 28 liquid-liquid systems from 13 different sources, and presented a unified correlation

(shown in Equation 3) for $E_{c}$ in pulsed sieve plate columns:

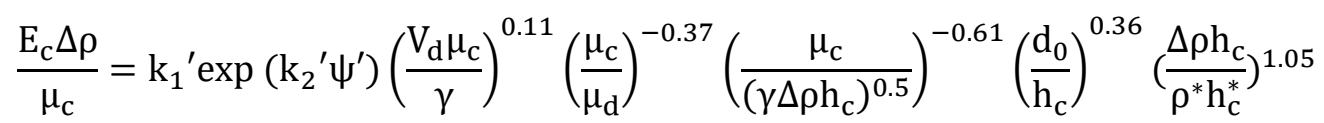

where the standard density of water $\rho^{*}=998 \mathrm{~kg} / \mathrm{m}^{3}$, standard plate spacing $\mathrm{h}_{\mathrm{c}}^{*}=0.05 \mathrm{~m}$, $\mathrm{k}_{1}{ }^{\prime}=46.15$ and $\mathrm{k}_{2}^{\prime}=0.80$ or 0.34 depending on pulsation intensity range. This correlation could be used with a wide range of systems and over a range of operating conditions.

\subsection{Mass transfer}

The mass transfer performance of an extraction column is usually determined as a height of mass transfer unit, including the apparent mass transfer unit $\mathrm{H}_{\mathrm{oxp}}$ and the true mass transfer unit $\mathrm{H}_{\mathrm{ox}}{ }^{36}$. The number of mass transfer units, $\mathrm{N}_{\mathrm{oxp}}$, and $\mathrm{H}_{\mathrm{oxp}}$ can be determined (as shown in Equation 4) with inlet and outlet solute concentrations of both 
column.

$$
\mathrm{N}_{\text {oxp }}=\int_{\mathrm{x}_{\text {out }}}^{\mathrm{x}_{\text {in }}} \frac{\mathrm{dx}}{\mathrm{x}-\mathrm{x}^{*} \text { plug flow }}, \quad \mathrm{H}_{\text {oxp }}=\frac{\mathrm{H}}{\mathrm{N}_{\text {oxp }}}
$$

$$
\mathrm{H}_{\mathrm{ox}}=\frac{\mathrm{V}_{\mathrm{c}}}{\mathrm{K}_{\mathrm{ox}} \mathrm{a}}, \quad \mathrm{N}_{\mathrm{ox}}=\frac{\mathrm{H}}{\mathrm{H}_{\mathrm{ox}}}
$$

Equation 5

$\mathrm{N}_{\mathrm{ox}}$ and $\mathrm{H}_{\mathrm{ox}}$ are defined in terms of the volumetric mass transfer coefficient $\mathrm{K}_{\mathrm{ox}}$ a (as shown in Equation 5) when the effect of axial dispersion is taken into account. When axial dispersion coefficients are given, by solving the coupled ordinary differential equations (ODEs) shown in Equation $6^{36}$ with inlet and outlet solute concentrations as boundary conditions, $\mathrm{K}_{\mathrm{ox}}$ a and $\mathrm{H}_{\mathrm{ox}}$ can be calculated.

$$
\begin{aligned}
& E_{d} \frac{d^{2} y}{d z^{2}}+V_{d} \frac{d y}{d z}+K_{o x} a\left(x-x^{*}\right)=0 \\
& E_{c} \frac{d^{2} x}{d z^{2}}-V_{c} \frac{d x}{d z}-K_{o x} a\left(x-x^{*}\right)=0
\end{aligned}
$$




$$
\mathrm{K}_{\mathrm{ox}} \mathrm{a}=\mathrm{k}_{1}^{\prime \prime} \mathrm{U}_{\mathrm{d}}^{\mathrm{k}_{2}^{\prime \prime}}\left(1+\mathrm{k}_{3}^{\prime \prime} \psi^{\mathrm{k}_{4}^{\prime \prime}}\right)
$$

127 where $\mathrm{k}_{1}^{\prime \prime}=30 \times 10^{-4}, \mathrm{k}_{2}^{\prime \prime}=0.76, \mathrm{k}_{3}^{\prime \prime}=8.8 \times 10^{-3}, \mathrm{k}_{4}^{\prime \prime}=0.85$ for benzoic acid with the

128 mass transfer direction of $\mathrm{d} \rightarrow \mathrm{c}$, and $\psi$ is the average power dissipation per unit mass.

\section{3. Experimental}

The two types of novel ceramic internals designed and manufactured for use in this 


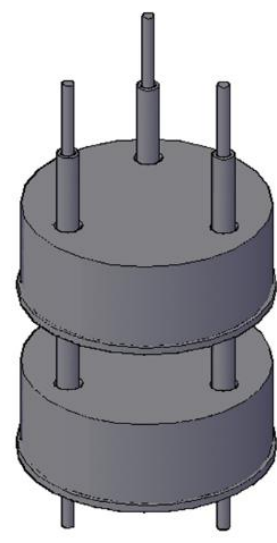

(A)

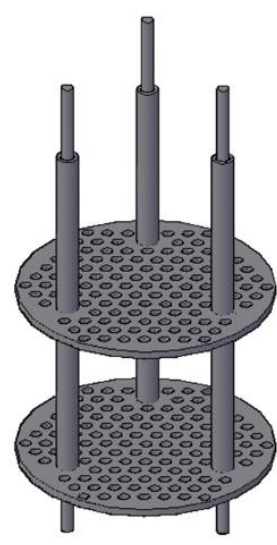

(B)

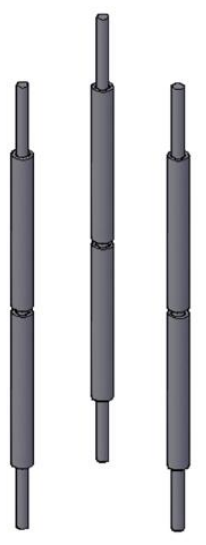

(C)

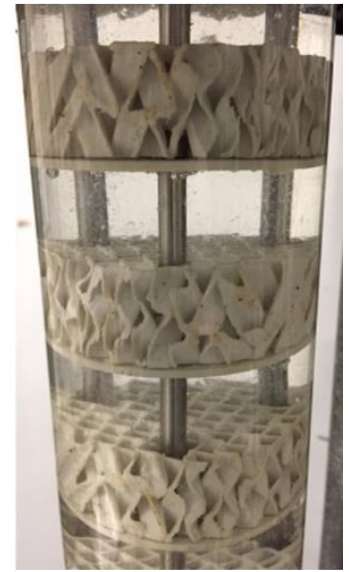

(D)
140

Figure 1 Schematic diagrams and photograph of ceramic internals (A) hybrid ceramic internal
(B) ceramic plate (C) tie rods
(D) photograph of hybrid ceramic internal

All experiments were performed in a pilot plant column, refer to process flow diagram shown in Figure $2^{39}$. This is made up of a $1.0 \mathrm{~m}$ long $\mathrm{QVF}^{\circledR}$ precision bore glass column with an internal diameter of $72.5 \mathrm{~mm}$. The organic phase outlet is a glass T-piece on top of the column body. The internal diameter of the glass section at the bottom of the column increases to $100 \mathrm{~mm}$ with a stainless steel distributor inside. A stainless steel conical adapter then reduces the diameter to $50 \mathrm{~mm}$ and is connected to a piston-type pulsing unit. This pulsing unit consists of a motor, a variable speed unit (controls the frequency), a variable eccentric drive head (controls the amplitude), a crank arm and a plunger equipped with a Teflon cylinder and two rubber seals in a stainless steel cylinder. Sinusoidal motion is provided by the plunger to the fluids in the column. 


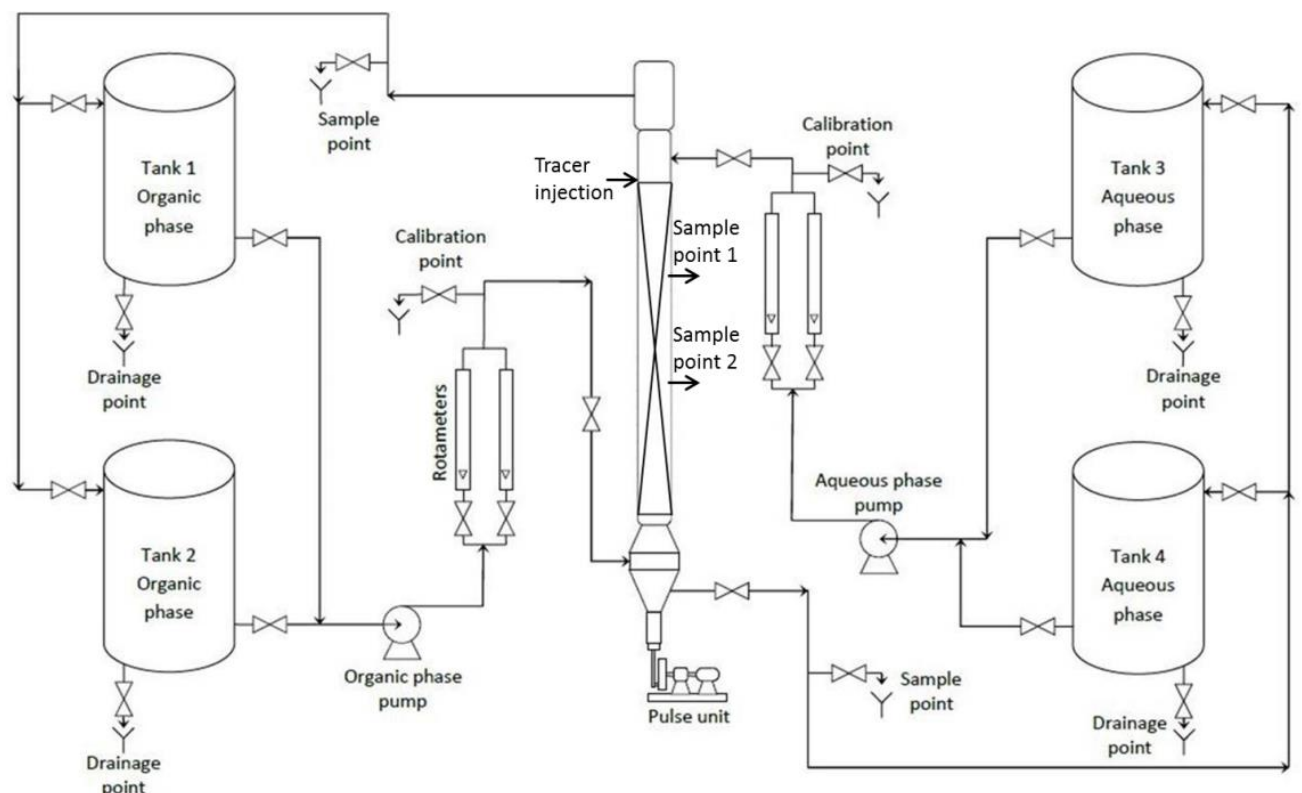

156 Myer (Shanghai) in Shellsol $2046^{\circledR}$, supplied by Shell Australia. Glacial acetic acid supplied by

157 Thermo Fisher is diluted in water and used as solute. The aqueous phase is tap water. The

158 tracer used in axial dispersion experiments is $1 \mathrm{w} \%$ tartrazine yellow (Acid yellow 23)

159 solution, supplied by Sigma Aldrich. The physical properties, including densities, viscosities

160 and interfacial tension were measured and are presented in Table 1 . This system is a widely

161 used standard system with medium interfacial tension to evaluate performance of new types of extraction column internals.

Table 1 Physical properties and solute equilibrium of the two phases

\begin{tabular}{lcc}
\hline & Aqueous & Organic \\
\hline Density $\left(\mathrm{kg} / \mathrm{m}^{3}\right)$ & 1008 & 844
\end{tabular}




$$
\begin{array}{lcc}
\text { Viscosity }(\mathrm{Pa} \cdot \mathrm{s}) & 1.06 \times 10^{-3} & 2.05 \times 10^{-3} \\
\text { Interfacial tension }(\mathrm{mN} / \mathrm{m}) & 10.1 \\
\text { Equilibrium relationship } & x^{*}=1.6306 \times y, \quad 0<y<0.11 \mathrm{~mol} / \mathrm{L}
\end{array}
$$
sampling points were set along the column height (as shown in Figure 2). The injection point

166 is located at the upper part of the column, while the two sample points are located in the

167 middle part of the column and are $30 \mathrm{~cm}$ apart from each other. All three points are sealed

168 with Teflon caps through which stainless steel sample tubes can be inserted. The column is 169 operated with a continuous aqueous phase and dispersed organic phase with the interface 170 maintained at the top of the column. In a typical experiment, aqueous phase samples are

171 taken continuously via a Watson Marlow 505 S peristaltic pump. The tracer concentration is 172 measured and recorded with two pre-calibrated UV/Vis spectrophotometers ( 723 , Shanghai 173 Jinghua Scientific\& Technology Instrument Co., Ltd.) which are equipped with a $10 \mathrm{~mm}$ path

174 length flow cell. To prevent the dispersed phase entering the sample tube, hydrophilic

175 stainless steel caps are added at the tip of the sample tubes.

177 relationship was measured within the concentration range used in the column experiments.

178 The equilibrium data can be well represented by a linear relationship (shown in Table 1),

179 which can be explained by the low concentration of solute. This feature also means that the 180 estimation method by Miyauchi et al. ${ }^{37}$ for $\mathrm{H}_{\mathrm{ox}}$ can be used with good accuracy. In a typical mass transfer experiment, the extraction column is operated under desired conditions for 
182

183

184

about 50 minutes until steady state condition is reached. At this point approximately $15 \mathrm{~mL}$ of each phase will be taken from the inlet and outlet as samples, and then analyzed by titration with pre-calibrated sodium hydroxide solution. $\mathrm{H}_{\mathrm{oxp}}$ and $\mathrm{N}_{\mathrm{oxp}}$ can then be calculated from the data via a pre-coded MATLAB program according to Equation 4. The results are considered reliable if the mass balance error is less than $10 \%$.

\section{Results and Discussion}

\subsection{Axial dispersion}

The continuous phase axial dispersion coefficient is determined with tracer concentration-time curves from the two sample points. A typical set of experimental data is shown in Figure 3(A), in which the curve from sample point 2 is lower and wider than that from sample point 1 as a result of axial dispersion. Once the experimental data is collected, the one-dimensional (axial direction) differential equation for tracer transport is solved with the first experimental curve as the boundary condition. Different value of $\mathrm{E}_{\mathrm{c}}$ will result in different prediction for the second curve, thus a searching method for $E_{c}$ is used to fit the predicted curve of sample point 2 with experimental data. Prediction of the two curves is also shown in Figure $3(\mathrm{~A})$ with the solid lines which are in good agreement with the experimental data. With the correctly fitted axial dispersion coefficient, tracer concentration distribution on the two-dimensional position-time domain is shown in Figure $3(\mathrm{~B})$ by solving the transport differential equation for the tracer. 


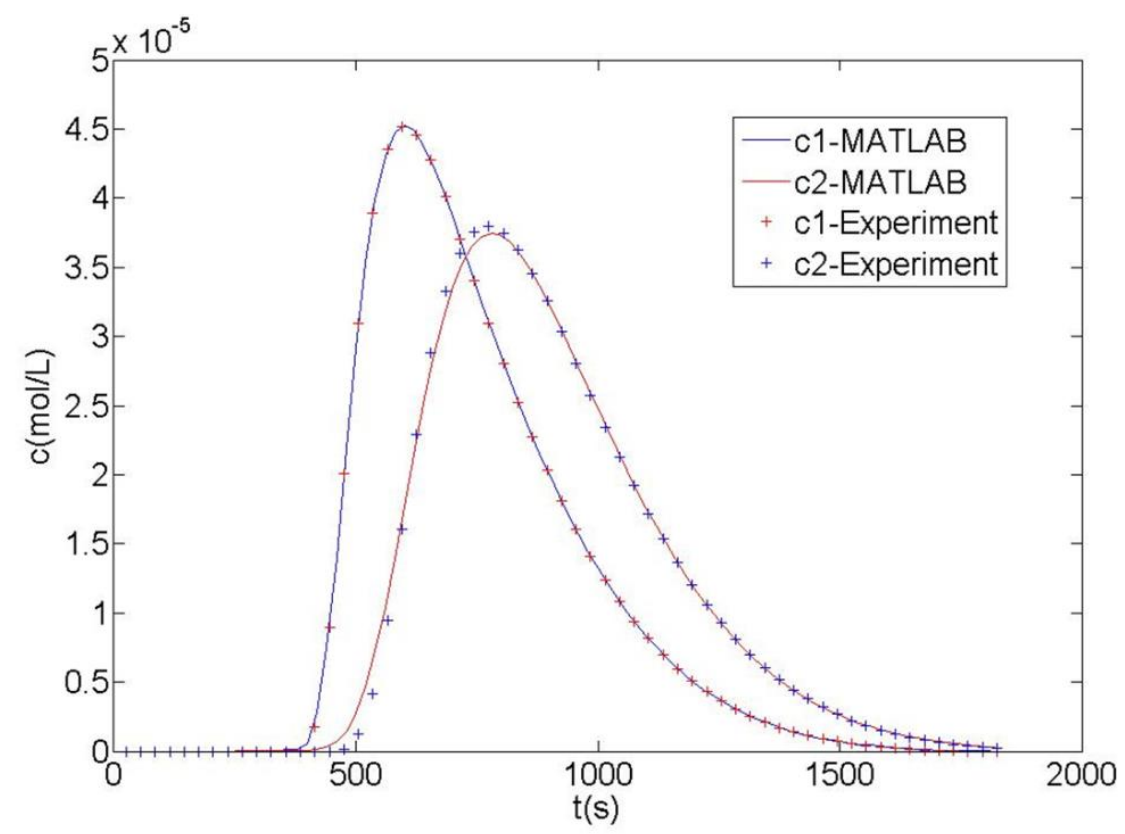

(A)

201

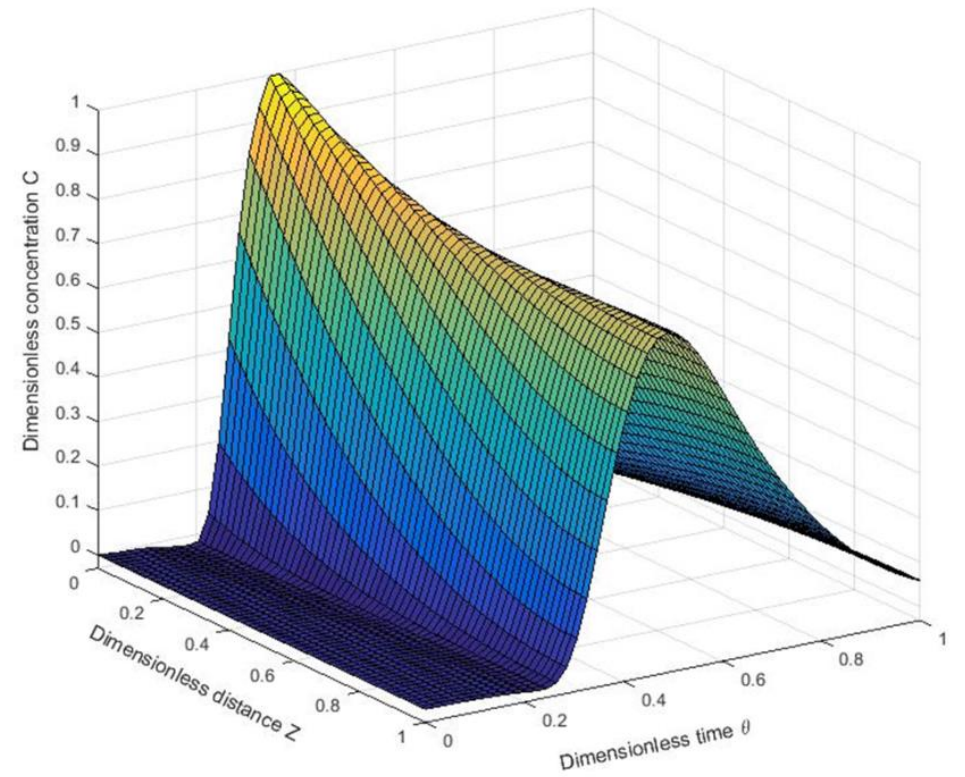

(B)

Figure 3 MATLAB program output for calculation of axial dispersion coefficient: (A) Typical experimental tracer concentration data with time and predicted curves at two sample points

(B) Reconstructed tracer distribution on two dimensional position-time domain 

Figure 6 , in which the effects of pulsation intensity and two phase velocity are considered.

Pulsation intensity varies from $0.3 \mathrm{~cm} / \mathrm{s}$ to $1.8 \mathrm{~cm} / \mathrm{s}$, while superficial velocities for

continuous and dispersed phase vary from $9 \times 10^{-4}$ to $2.3 \times 10^{-3} \mathrm{~m} / \mathrm{s}$ and $6 \times 10^{-4}$ to $2.1 \times 10^{-3}$

$\mathrm{m} / \mathrm{s}$ respectively. In these figures, experimental data is shown with points, while the solid

lines are the predicted values of correlation regressed from experimental data which will be

discussed later. $E_{c}$ for both types of internals slightly increases with an increase of

explained by the fact that no experiments were conducted with an amplitude that exceeds

the free spacing between the stages, which significantly increases the axial dispersion. To to vary by $10.9 \%$ while that of hybrid ceramic internal is $7.5 \%$. ceramic plate by about $1 / 2$ under all the conditions investigated. This means the flow is

222 more plug flow like for the hybrid ceramic internal, which results in better mass transfer ceramic internals is that adding the packing on the ceramic plates reduces the free spacing between the stages, where axial dispersion is most likely to occur. The explanation is reasonable when considering that the ratio of free spacing between the two types of ceramic internals is about $1 / 2$, which is the same as the ratio of experimental $E_{c}$ variation. 


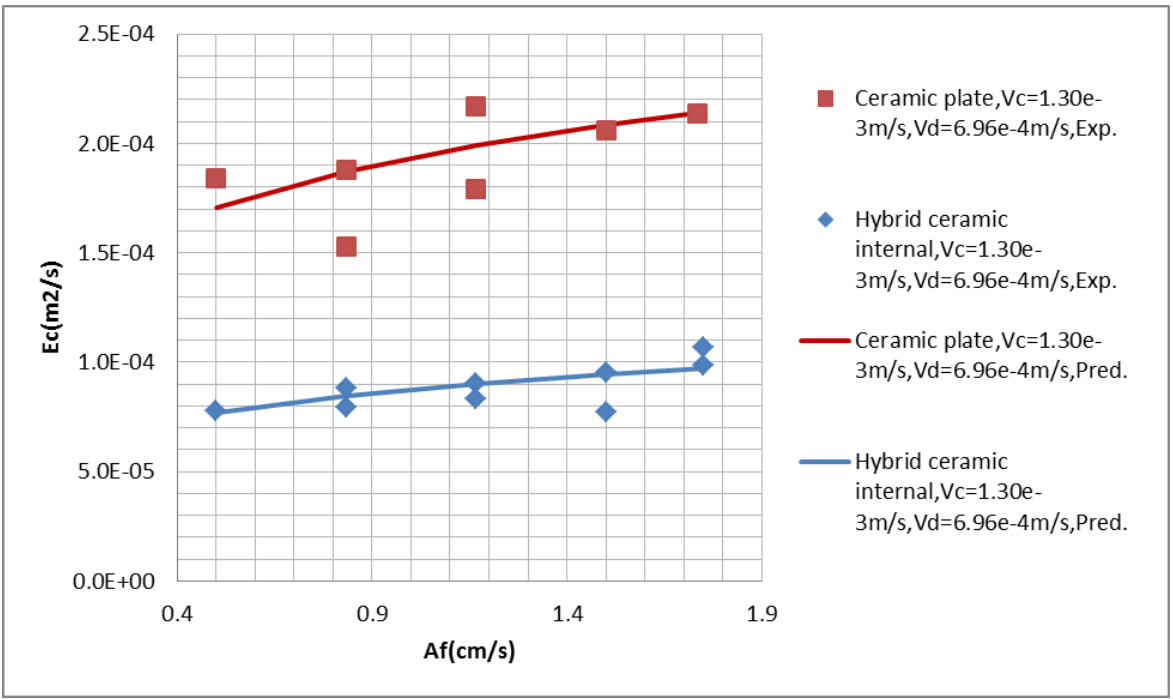

229 Figure 4 Effect of pulsation intensity on axial dispersion coefficients for two types of ceramic internals

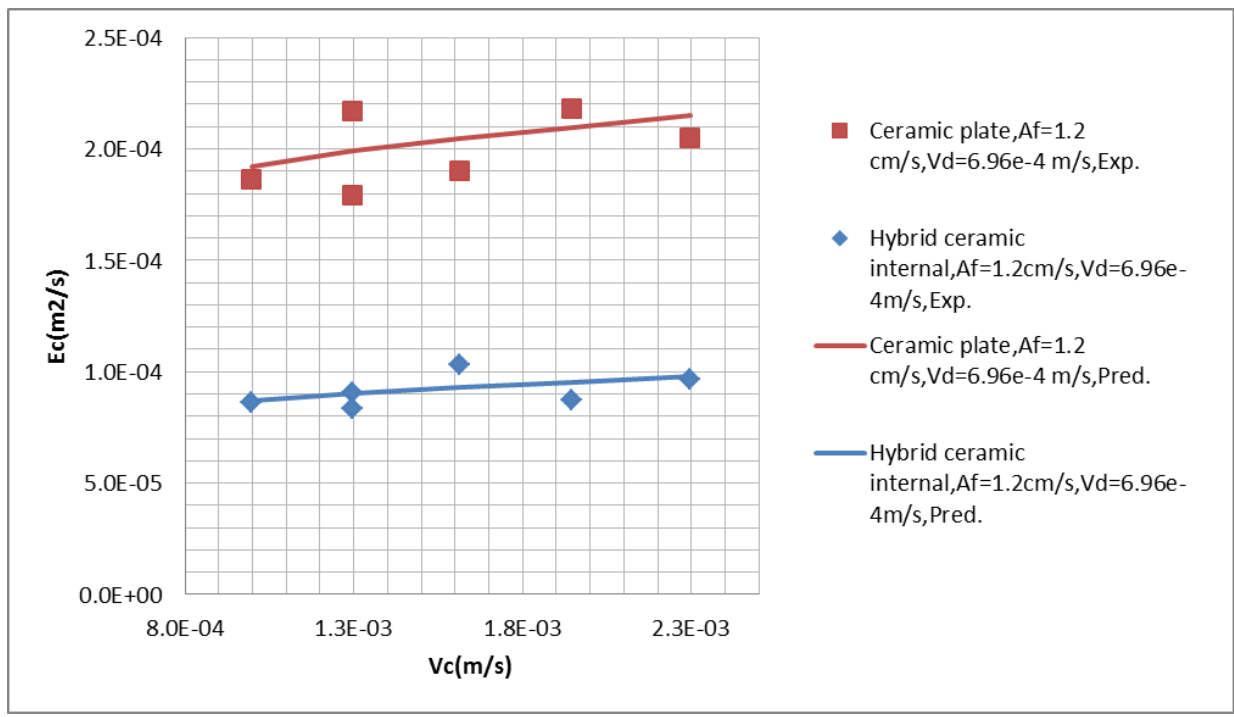

232 Figure 5 Effect of continuous phase velocity on axial dispersion coefficients for two types of 


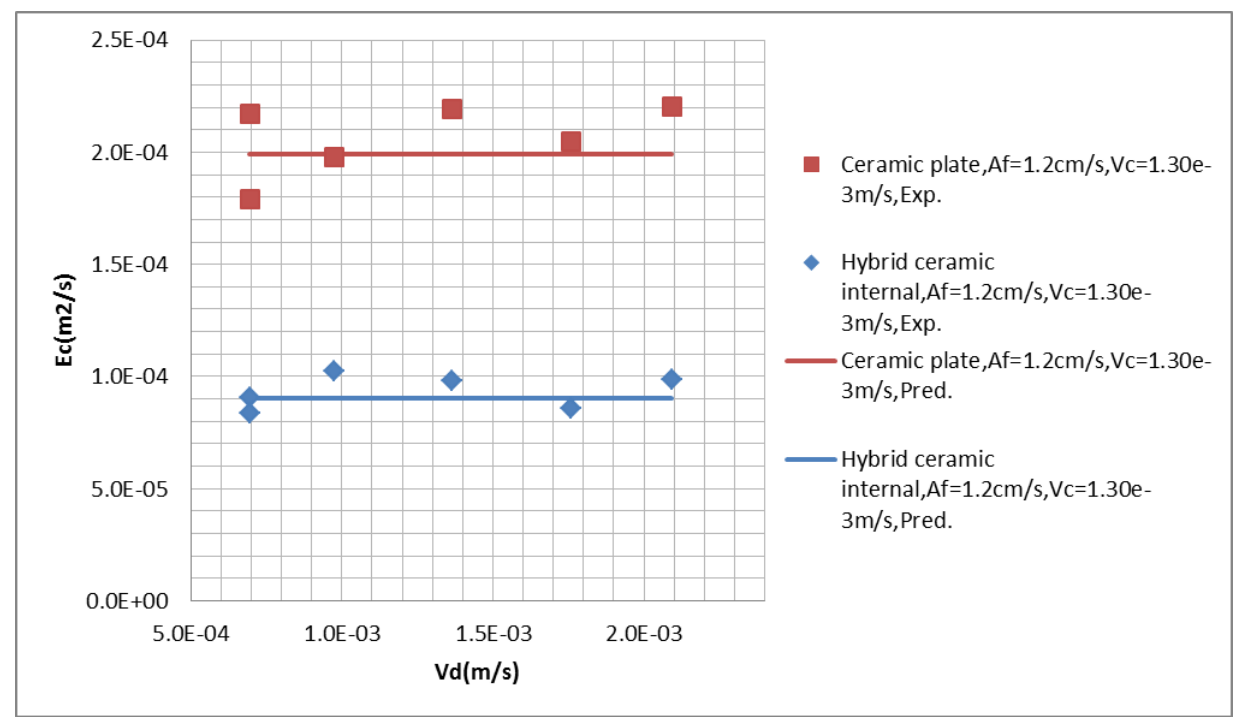

Figure 6 Effect of dispersed phase velocity on axial dispersion coefficients for two types of

238 based on Equation 2. The parameters $\mathrm{k}_{1}$ to $\mathrm{k}_{3}$ in Equation 2 are refitted, while values of

$239 \mathrm{k}_{4}$ and $\mathrm{k}_{5}$ for emulsion region are taken from Srinikethan et al. ${ }^{35}$ The parameters for the

$$
\mathrm{ARD}=\frac{1}{\mathrm{n}} \sum_{1}^{\mathrm{n}} \frac{\mid \text { predicted value }- \text { experimental value } \mid}{\text { experimental value }} \times 100 \%
$$


Hybrid ceramic internal

6.4506

0.1916

0.6729

0.8

$-0.8$

$6.0 \%$

Ceramic plate

14.8636

0.1815

0.6885

0.8

$-0.8$

$6.9 \%$

With the refitted parameters, the ARD for the hybrid ceramic internal and ceramic plate are $6.0 \%$ and $6.9 \%$ respectively. The predicted $E_{c}$ is also compared with experimental data in Figure 4, Figure 5 and Figure 6 , and the predicted $E_{c}$ (shown by solid lines) agrees well with the experimental data shown as discretized points. A systematic comparison is shown in Figure 7, in which the deviation between prediction and experiments are within $10 \%$.

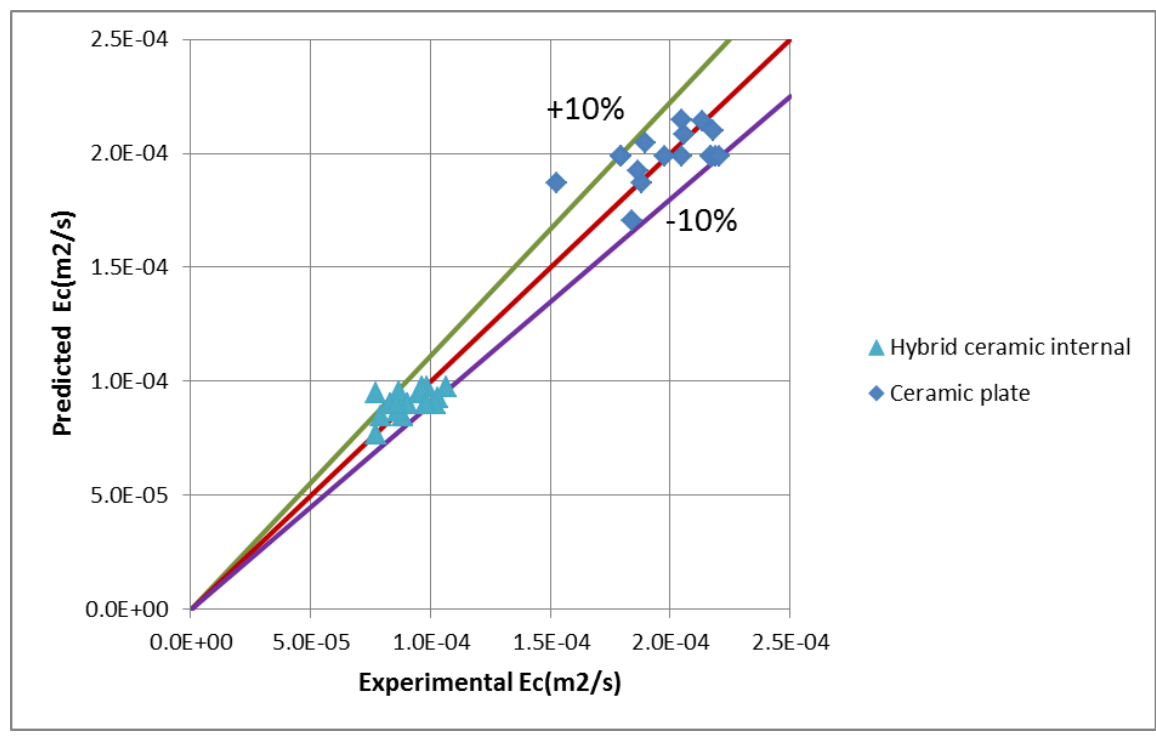

Figure 7 Experimental and predicted axial dispersion coefficients from refitted Equation 2 using constants from Table 2

\subsection{Mass transfer}

Systematic mass transfer experiments were performed to compare the mass transfer performance of the two types of internals. The results are shown in Figure 8 and Figure 9, in

257 which the effects of pulsation intensity and two phase superficial velocity are considered. 
ratio varies from 0.5 to 2 while total throughput of the two phases is kept constant. When the effect of dispersed phase velocity is investigated, $V_{d}$ varies from $6 \times 10^{-4}$ to $3.5 \times 10^{-3}$ $\mathrm{m} / \mathrm{s}$. With an increase of pulsation intensity, $\mathrm{H}_{\mathrm{oxp}}$ (calculated according to Equation 4) decreases accordingly for both types of internals under every $V_{c} / V_{d}$ condition, indicating an improvement in mass transfer efficiency. For each type of internal, $\mathrm{H}_{\text {oxp }}$ decreases when $V_{c} / V_{d}$ decreases from 2 to 0.5 . The effect of $V_{d}$ on $H_{\text {oxp }}$ is shown in Figure 9 , in which $\mathrm{H}_{\mathrm{oxp}}$ decreases with an increase of $\mathrm{V}_{\mathrm{d}}$. With the ceramic packing added, the hybrid ceramic internal has lower $\mathrm{H}_{\text {oxp }}$ than ceramic plate by around $40 \%$ under all the conditions investigated, which means $40 \%$ in reduction of column height for a given separation task.

\section{This can be partly explained by the less non-ideality caused by axial dispersion for hybrid} ceramic internal discussed in the previous part. Higher volumetric mass transfer coefficient resulted from the add of packing may be another cause, and this possibility will be discussed in the following parts. It should be noted that under the best condition, $\mathrm{H}_{\mathrm{oxp}}$ of the hybrid ceramic internal is as low as $0.2 \mathrm{~m}$, which indicates very good mass transfer efficiency.

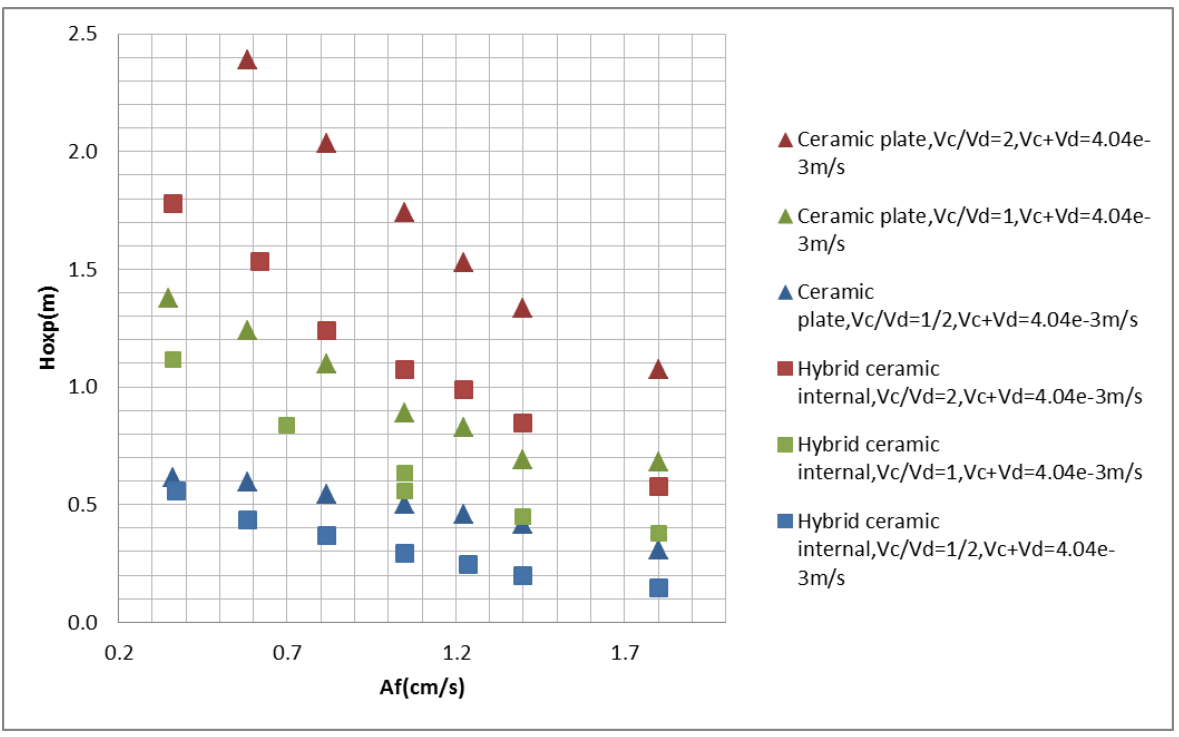



apparent mass transfer unit for two types of ceramic internals

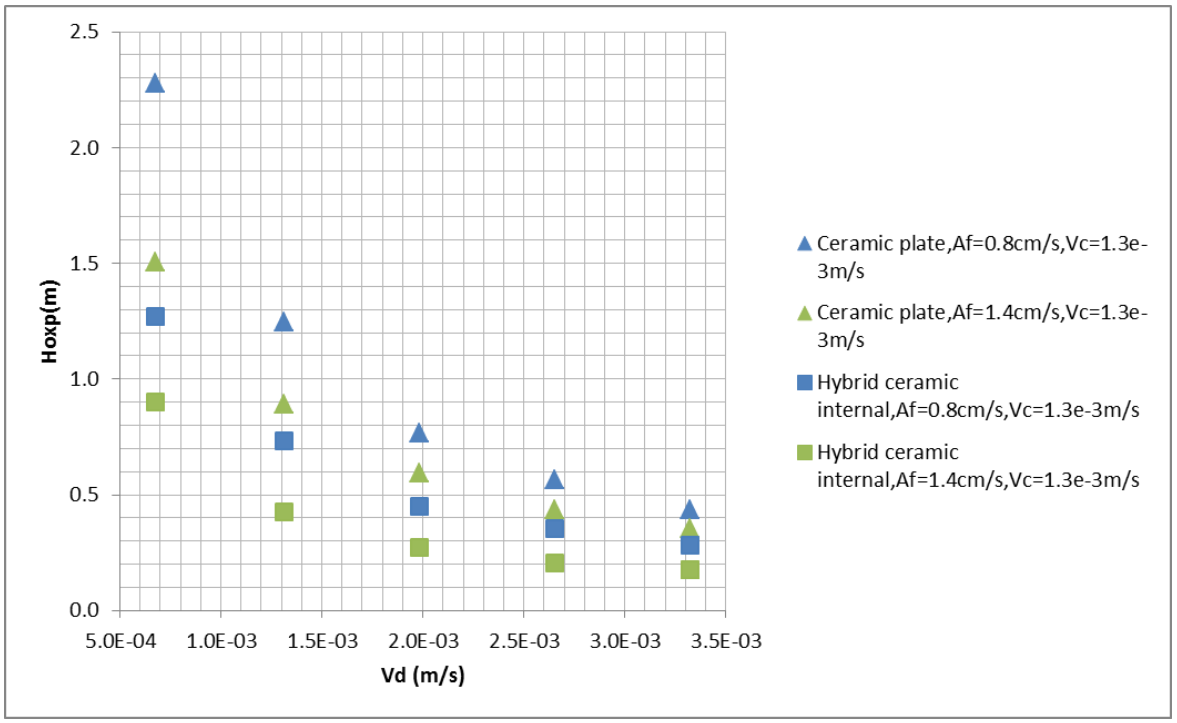

277 Figure 9 Effect of dispersed phase velocity on height of apparent mass transfer unit for two types of ceramic internals The accuracy of the mass transfer experimental data is checked via mass balance, and 280 the results are shown in Figure 10. All the data points are located in the region with an error of less than $10 \%$ indicating the collected data has high accuracy. 


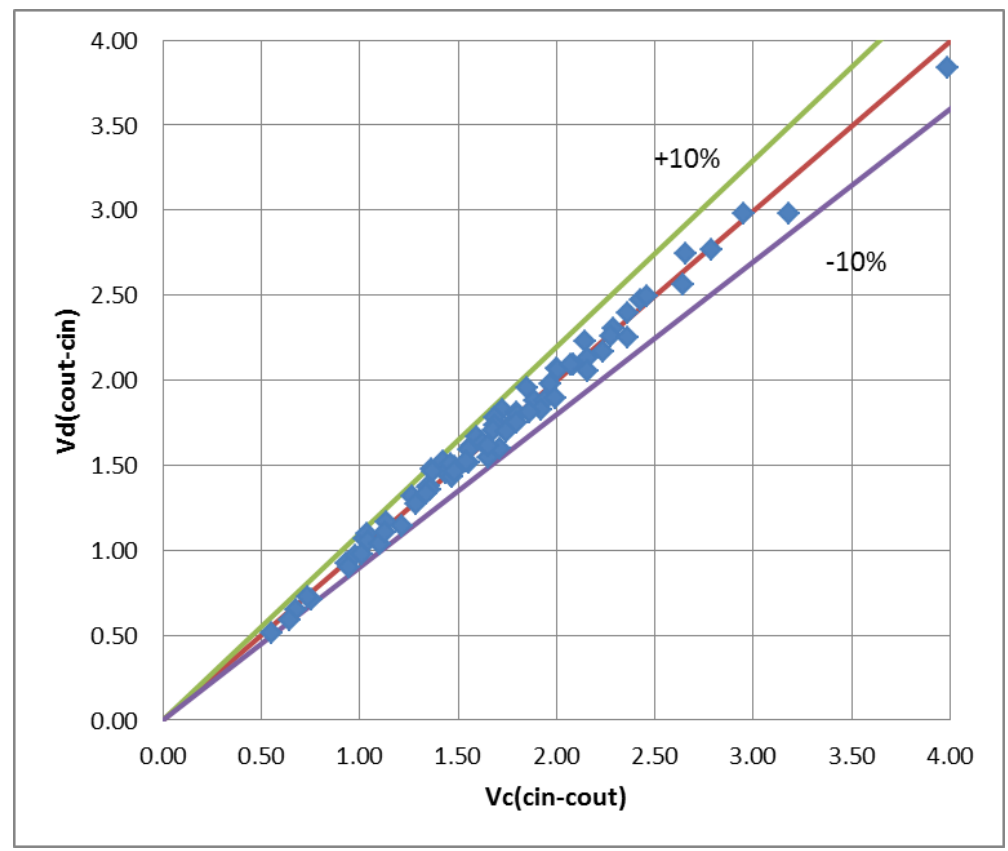

Figure 10 Solute mass balance for all mass transfer experiments

Using the overall mass transfer data and continuous phase axial dispersion coefficient predicted with refitted Equation 2, the volumetric mass transfer coefficient, $\mathrm{K}_{\mathrm{ox}} \mathrm{a}$, can be calculated using the axial dispersion model ${ }^{37}$. The calculated values of $\mathrm{K}_{\mathrm{ox}} \mathrm{a}$ are shown in Figure 11 and Figure 12 as a function of pulsation intensity and dispersed phase velocity respectively. $\mathrm{K}_{\mathrm{Ox}} \mathrm{a}$ increases with an increase of pulsation intensity and dispersed phase velocity, and a decrease of $\mathrm{V}_{\mathrm{c}} / \mathrm{V}_{\mathrm{d}}$. Increased dispersed phase velocity increases holdup, and higher pulsation intensity results in smaller Sauter mean diameter for droplets for these two

291 internals ${ }^{25}$. These two factors contribute to higher specific interfacial area, thus can be an explanation for the trend of $\mathrm{K}_{\mathrm{ox}} \mathrm{a}$. With the ceramic packing added, hybrid ceramic internal

293 has higher $\mathrm{K}_{\mathrm{ox}}$ a than ceramic plate by around $50 \%$ under the range of conditions investigated in this study. Hydrodynamic experimental results by Yi et al. ${ }^{25}$ shows that holdup of hybrid ceramic internal is higher than that of ceramic plate by around $50 \%$, and Sauter mean diameter $d_{32}$ of hybrid ceramic internal is smaller than that of ceramic plate 


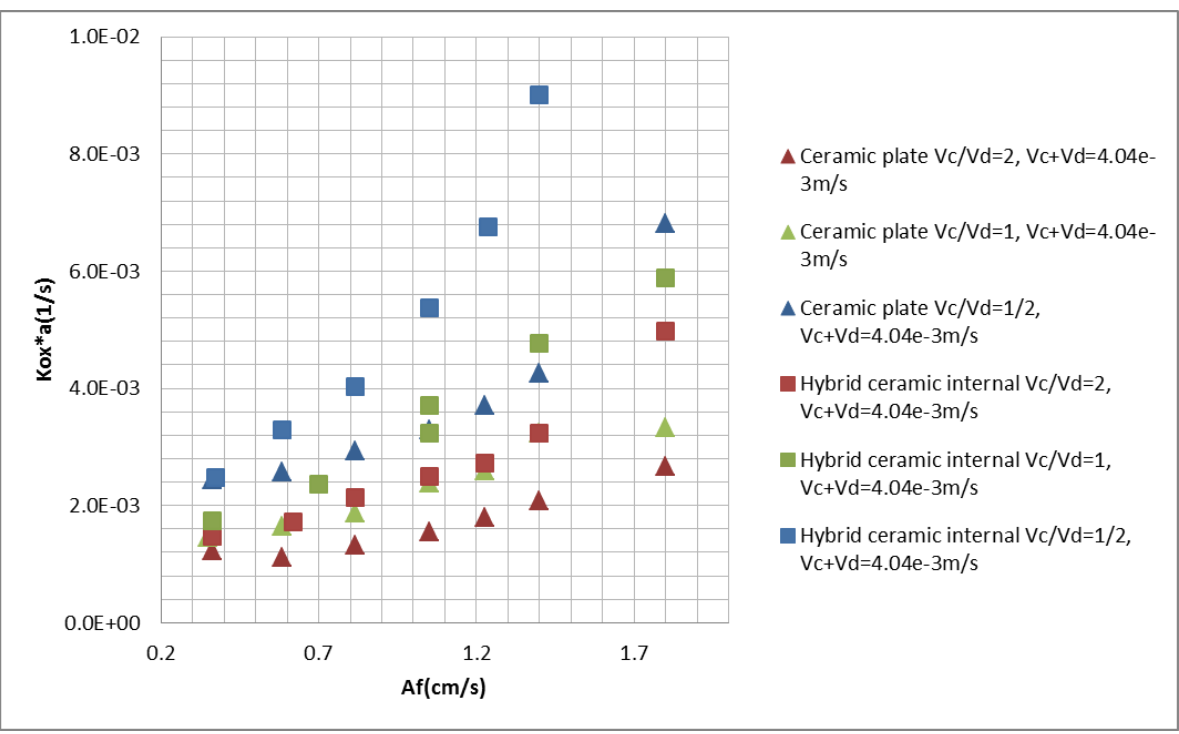

Figure 11 Effect of pulsation intensity and continuous-dispersed phase ratio on volumetric mass transfrer coefficient for two types of ceramic internals

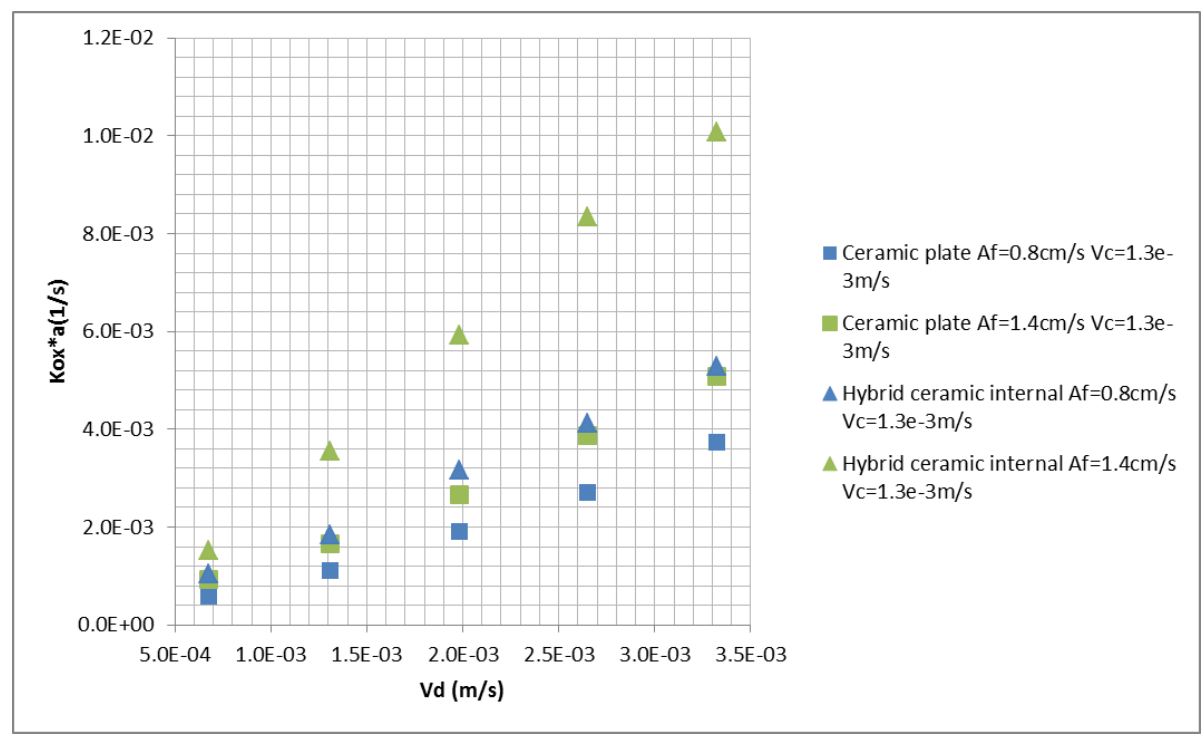



with values shown in Table 3.

Table 3 Parameters for predicting the mass transfer coefficient using refitted Equation 7 for the two types of ceramic internals in this study

\begin{tabular}{cccccc}
\hline Internals & $\mathrm{k}_{1}^{\prime \prime}$ & $\mathrm{k}_{2}^{\prime \prime}$ & $\mathrm{k}_{3}^{\prime \prime}$ & $\mathrm{k}_{4}^{\prime \prime}$ & ARD \\
\hline Hybrid ceramic internal & 6.4195 & 1.3230 & 0.2744 & 0.8121 & $12.0 \%$ \\
Ceramic plate & 3.0246 & 1.2047 & 0.0637 & 0.9515 & $7.0 \%$ \\
\hline
\end{tabular}
$\mathrm{K}_{\mathrm{ox}} \mathrm{a}$ is shown in Figure 13, in which the deviations are within $20 \%$.

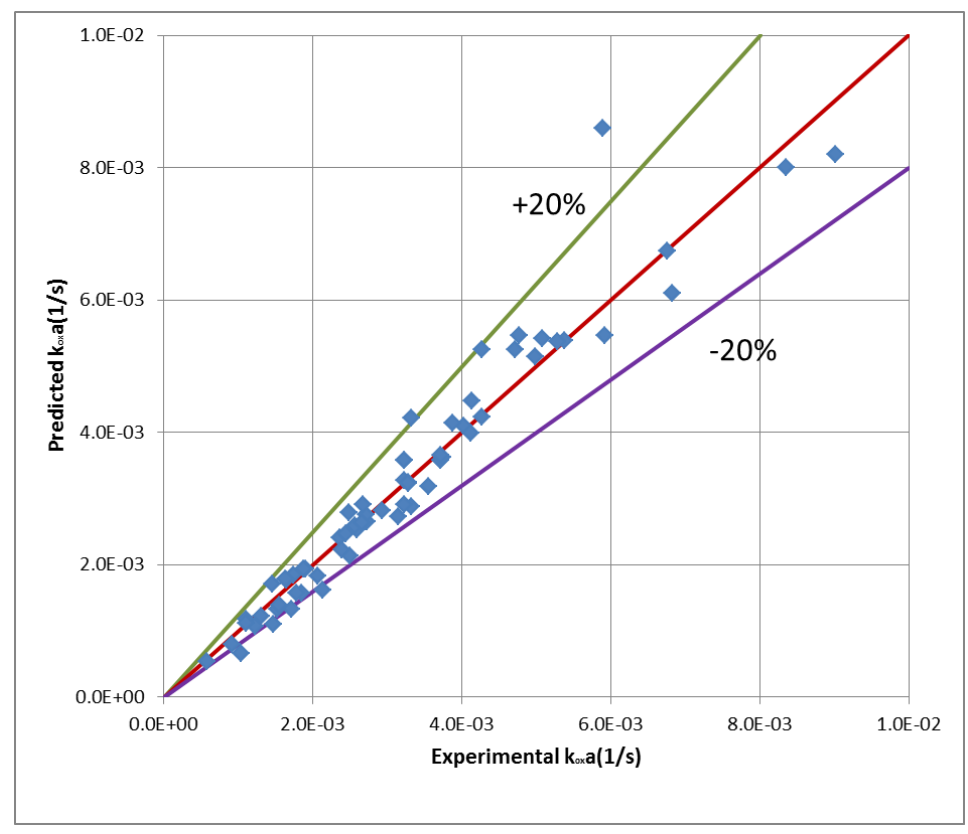




\section{Conclusions}

Two types of novel anti-corrosive ceramic internals for a pulsed solvent extraction

column were designed and pilot plant experiments were performed with standard

liquid-liquid system to evaluate and compare their axial dispersion and mass transfer

performance. The conclusions from this study can be summarized as follows:

1. Axial dispersion coefficients, $E_{c}$, of the hybrid ceramic internal is less than that of the ceramic plate by around $50 \% . \mathrm{E}_{\mathrm{c}}$ for both types of internals slightly increases with the

2. A correlation for $E_{c}$ is chosen and refitted to predict the experimental data, and the ARD for the hybrid ceramic internal and ceramic plate are $6.0 \%$ and $6.9 \%$ respectively.

3. The height of mass transfer unit, $\mathrm{H}_{\mathrm{oxp}}$, of the hybrid ceramic internal is less than that

4. Volumetric mass transfer coefficient, $\mathrm{K}_{\mathrm{ox}} \mathrm{a}$, for both types of ceramic internals are calculated, and results show that $\mathrm{K}_{\mathrm{Ox}} \mathrm{a}$ of hybrid ceramic internal is higher than that of ceramic plate by around $50 \%$.

5. A correlation for $\mathrm{K}_{\mathrm{Ox}} \mathrm{a}$ is chosen and refitted to predict the experimental data, and the ARD for hybrid ceramic internal and ceramic plate are $12.0 \%$ and $7.0 \%$ respectively. 
337 W.Y. Fei: Tel: $+861062789637 . \quad$ E-mail: fwy-dce@tsinghua.edu.cn

\section{- Acknowledgements}

340 The authors would like to acknowledge the funding provided by the Australian Research

341 Council through Linkage grant LP130100305, and would also like to thank the Particulate Fluids Processing Centre for the resources provided for this project.

\section{- Nomenclature}

$344 \quad$ A: amplitude, $m$

345 a: specific interfacial area, $\mathrm{m}^{2} / \mathrm{m}^{3}$

346 ARD: average relative deviation, dimensionless

347 c: tracer concentration, $\mathrm{mol} / \mathrm{L}$

348 d32: Sauter-mean drop diameter, $m$

349 d0: plate perforation diameter, $\mathrm{m}$

$350 \quad$ E: axial dispersion coefficient, $\mathrm{m}^{2} / \mathrm{s}$

351 f: frequency, $\mathrm{Hz}$

$352 \mathrm{H}$ : height of effective part of the column, $m$

$353 \mathrm{H}_{\mathrm{ox}}$ : height of true mass transfer unit, $\mathrm{m}$

$354 \quad \mathrm{H}_{\text {oxp }}$ : height of apparent mass transfer unit, $m$ 
355 hc: compartment height, $\mathrm{m}$

$356 \mathrm{~h}_{\mathrm{c}}^{*}$ : standard compartment height, $\mathrm{m}$

$357 \quad \mathrm{~K}_{\mathrm{ox}}$ : mass transfer coefficient, $\mathrm{m} / \mathrm{s}$

$358 \quad \mathrm{k}_{1}$ to $\mathrm{k}_{5}$ : constants in Equation 2, dimensionless

$359 \quad \mathrm{k}_{1}{ }^{\prime}$ to $\mathrm{k}_{2}{ }^{\prime}$ : constants in Equation 3, dimensionless

$360 \quad \mathrm{k}_{1}{ }^{\prime \prime}$ to $\mathrm{k}_{4}{ }^{\prime \prime}$ : constants in Equation 7, dimensionless

$361 \mathrm{~N}_{\text {oxp }}$ : number of apparent mass transfer unit, dimensionless

$362 \mathrm{~N}_{\mathrm{OX}}:$ number of true mass transfer unit, dimensionless

$363 \quad$ V : superficial velocity, $\mathrm{m} / \mathrm{s}$

$364 \mathrm{x}$ : solute concentration in aqueous phase, $\mathrm{mol} / \mathrm{m}^{3}$

$365 \mathrm{x}^{*}$ : equilibrium solute concentration of the contacting dispersed phase, $\mathrm{mol} / \mathrm{m}^{3}$

$366 \mathrm{y}$ : solute concentration in dispersed phase, $\mathrm{mol} / \mathrm{m}^{3}$

$367 x \mathrm{~d}$ : volume fraction holdup of the dispersed phase, dimensionless

368 Greek Symbols

$369 \alpha$ : fractional free area of perforated plate, dimensionless

$370 \quad \gamma$ : interfacial tension, $\mathrm{N} / \mathrm{m}$

$371 \mu$ : viscosity, Pa.s

$372 \rho:$ density, $\mathrm{kg} / \mathrm{m}^{3}$

$373 \rho^{*}:$ standard density of water at $200 \mathrm{C}, \mathrm{kg} / \mathrm{m}^{3}$

$374 \Delta \rho$ : density difference between phases, $\mathrm{kg} / \mathrm{m}^{3}$

$375 \psi$ : average power dissipation per unit mass, $\mathrm{W} / \mathrm{kg}$

$376 \psi^{\prime}$ : translated agitation group in Equation 3, dimensionless 
Subscripts

c : continuous phase

$\mathrm{d}$ : dispersed phase

in: inlet of phases

out: outlet of phases

\section{- References}

(1) Hanson, C., Recent advances in liquid-liquid extraction. Elsevier: 1971.

(2) Thornton, J. D., Science and Practice of Liquid-liquid Extraction: Process chemistry and extraction operations in the hydrometallurgical, nuclear, pharmaceutical, and food industries. Oxford University Press, USA: 1992; Vol. 2.

(3) Jiading, W.; Weiyang, F., Recent Advances in Solvent Extraction. Prog. Chem. 1995, 7, 219-222.

(4) Sen, N.; Singh, K.; Patwardhan, A.; Mukhopadhyay, S.; Shenoy, K., CFD simulation of two-phase flow in pulsed sieve-plate column-Identification of a suitable drag model to predict dispersed phase hold up. Sep. Sci. Technol. 2016, 1-14.

(5) Sen, N.; Singh, K.; Patwardhan, A.; Mukhopadhyay, S.; Shenoy, K., CFD Simulations of Pulsed Sieve Plate Column: Axial Dispersion in Single-Phase Flow. Sep. Sci. Technol. 2015, 50, 2485-2495.

(6) Jaradat, M.; Attarakih, M.; Bart, H.-J. r., Population balance modeling of pulsed (packed and sieve-plate) extraction columns: Coupled hydrodynamic and mass transfer. Ind. Eng. Chem. Res. 2011, 50, 14121-14135.

(7) Jaradat, M.; Attarakih, M.; Bart, H.-J., Advanced prediction of pulsed (packed and sieve plate) extraction columns performance using population balance modelling. Chem. Eng. Res. Des. 2011, 89, 2752-2760.

(8) Yadav, R.; Patwardhan, A., Design aspects of pulsed sieve plate columns. Chem. Eng. J. 2008, 138, 389-415.

(9) Fei, W., Progresses of study and application on extraction columns. J Chem. Ind. Eng. (China) 2013, 64, 44-51.

(10) Grinbaum, B., Review Article: The Existing Models for Simulation of Pulsed and Reciprocating Columns-How Well do they Work in the Real World? Solvent Extr. Ion Exch. 2006, 24, 795-822.

(11) Lade, V. G.; Rathod, V. K.; Bhattacharyya, S.; Manohar, S.; Wattal, P. K., Comparison of normal phase operation and phase reversal studies in a pulsed sieve plate extraction column. Chem. Eng. Res. Des. 2013, 91, 1133-1144. 
(12) Khawaja, S.; Usman, M.; Khan, S.; Afzal, W.; Akhtar, N., Dispersed Phase Holdup in a Tall and Low Plate Free Area Liquid Pulsed Sieve-Plate Extraction Column. Sep. Sci. Technol. 2013, 48, 175-182.

(13) Ousmane, S.; Isabelle, M.; Mario, M.-S.; Mamadou, T.; Jacques, A., Study of mass transfer and determination of drop size distribution in a pulsed extraction column. Chem. Eng. Res. Des. 2011, 89, 60-68.

(14) Din, G. U.; Chughtai, I. R.; Inayat, M. H.; Khan, I. H.; Qazi, N. K., Modeling of a two-phase countercurrent pulsed sieve plate extraction column-a hybrid CFD and radiotracer RTD analysis approach. Sep. Purif. Technol. 2010, 73, 302-309.

(15) Lade, V. G.; Pakhare, A. D.; Rathod, V. K., Mass transfer studies in pulsed sieve plate extraction column for the removal of tributyl phosphate from aqueous nitric acid. Ind. Eng. Chem. Res. 2014, 53, 4812-4820.

(16) Torab-Mostaedi, M.; Safdari, J.; Ghaemi, A., Mass transfer coeficients in pulsed perforated-plate extraction columns. Brazilian Journal of Chemical Engineering 2010, 27, 243-251.

(17) Nabli, M. A.; Guiraud, P.; Gourdon, C., Numerical experimentation: a tool to calculate the axial dispersion coefficient in discs and doughnuts pulsed solvent extraction columns. Chem. Eng. Sci. 1997, 52, 2353-2368.

(18) Kolhe, N.; Mirage, Y.; Patwardhan, A.; Rathod, V.; Pandey, N.; Mudali, U. K.; Natarajan, R., CFD and experimental studies of single phase axial dispersion coefficient in pulsed sieve plate column. Chem. Eng. Res. Des. 2011, 89, 1909-1918.

(19) Ghiyas Ud, D.; Imran Rafiq, C.; Hameed Inayat, M.; Hussain Khan, I., Study of axial mixing, holdup and slip velocity of dispersed phase in a pulsed sieve plate extraction column using radiotracer technique. Appl. Radiat. Isot. 2009, 67, 1248-1253.

(20) Liu, X.; Zhong, H.; Tang, Z., Current status and existing problems of lithium extraction technology from salt lake. Inorg. Chem. Ind. 2009, 6.

(21) Ferreira, A. E.; Agarwal, S.; Machado, R. M.; Gameiro, M. L. F.; Santos, S. M. C.; Reis, M. T. A.; Ismael, M. R. C.; Correia, M. J. N.; Carvalho, J. M. R., Extraction of copper from acidic leach solution with Acorga M5640 using a pulsed sieve plate column. Hydrometallurgy 2010, 104, 66-75.

(22) Gameiro, M. L. F.; Machado, R. M.; Ismael, M. R. C.; Reis, M. T. A.; Carvalho, J. M. R., Copper extraction from ammoniacal medium in a pulsed sieve-plate column with LIX 84-I. J. Hazard. Mater. 2010, 183, 165-175.

(23) Ikeda, H.; Suzuki, A., Wettability effects of plate materials on hydrodynamics in a pulsed perforated-plate extraction column of pulser feeder type. Ind. Eng. Chem. Res. 1995, 34, 4110-4117.

(24) Sobotik, R. H.; Himmelblau, D., The effect of plate wetting characteristics on pulse column extraction efficiency. AIChE J. 1960, 6, 619-624.

(25) Yi, H.; Wang, Y.; Smith, K. H.; Fei, W.; Stevens, G. W., Hydrodynamic Performance of a Pulsed Solvent Extraction Column with Novel Ceramic Internals: Holdup and Drop Size. Ind. Eng. Chem. Res. 2016.

(26) Bart, H.-J.; Stevens, G. W., Ion exchange and solvent extraction. Marcel Dekker, Inc.: New York, 2004. 
455

456

457

458

459

460

461

462

463

464

465

466

467

468

469

470

471

472

473

474

475

476

477

478

479

480

481

482

483

484
(27) Din, G. U.; Chughtai, I. R.; Inayat, M. H.; Khan, I. H., Axial dispersion, holdup and slip velocity of dispersed phase in a pulsed sieve plate extraction column by radiotracer residence time distribution analysis. Appl. Radiat. Isot. 2008, 66, 1818-1824.

(28) Kumar, A.; Hartland, S., Prediction of continuous-phase axial mixing coefficients in pulsed perforated-plate extraction columns. Ind. Eng. Chem. Res. 1989, 28, 1507-1513.

(29) Prvcic, L. M.; Pratt, H.; Stevens, G. W., Axial dispersion in pulsed - , perforated - plate extraction columns. AlChE J. 1989, 35, 1845-1855.

(30) Stella, A.; Pratt, H. R. C.; Mensforth, K. H.; Stevens, G. W.; Bowser, T., Backmixing in Karr Reciprocating-Plate Extraction Columns. Ind. Eng. Chem. Res. 2006, 45, 6555-6562.

(31) Kim, S. D.; Baird, M. H. I., Axial-dispersion in a reciprocating plate extraction column. Can. J Chem. Eng. 1976, 54, 81-89.

(32) Geankoplis, C. J.; Sapp, J. B.; Arnold, F. C.; Marroquin, G., Axial-Dispersion Coefficients of the Continuous Phase in Liquid-Liquid Spray Towers. Ind. Eng. Chem. Fundam. 1982, 21, 306-311.

(33) Kagan, S. Z.; Aerov, M. E.; Lonik, V.; Volkova, T. S., Some hydrodynamic and mass-transfer problems in pulsed sieve-plate extractors. Int. Chem. Eng. 1965, 5, 656-661.

(34) Tung, L. S.; Luecke, R. H., Mass-transfer and drop sizes in pulsed-plate extraction columns. Ind. Eng. Chem. Proc. DD 1986, 25, 664-673.

(35) Srinikethan, G.; Prabhakar, M. A.; Varma, Y., Axial dispersion in plate-pulsed columns. Bioprocess. Eng. 1987, 2, 161-168.

(36) Sleicher, C., Axial mixing and extraction efficiency. AlChE J. 1959, 5, 145-149.

(37) Miyauchi, T.; Vermeulen, T., Longitudinal dispersion in two-phase continuous-flow operations. Ind. Eng. Chem. Fundam. 1963, 2, 113-126.

(38) Harikrishnan, T.; Prabhavathy, N.; Varma, Y., Liquid-liquid mass transfer in a reciprocating-plate column. Chem. Eng. J Bioch. Eng. 1994, 54, 7-16.

(39) Wang, Y.; Mumford, K. A.; Smith, K. H.; Li, Z.; Stevens, G. W., Dispersed-Phase Holdup and Characteristic Velocity in a Pulsed and Nonpulsed Disk-and-Doughnut Solvent Extraction Column. Ind. Eng. Chem. Res. 2016, 55, 714-721. 


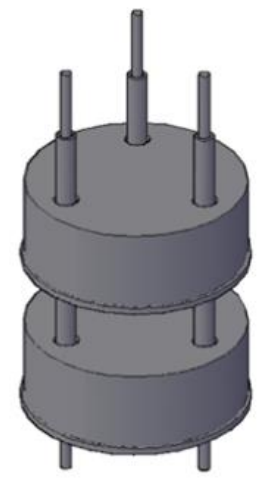

Hybrid ceramic 486 487 internal
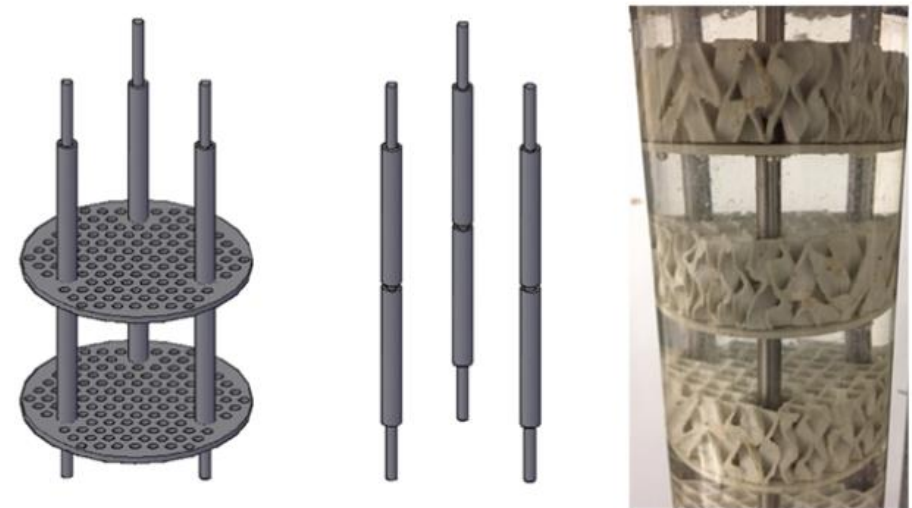

Ceramic plate 


\section{University Library}

\section{- M M N E R VA A gateway to Melbourne's research publications}

Minerva Access is the Institutional Repository of The University of Melbourne

Author/s:

Yi, H;Wang, Y;Smith, KH;Fei, W;Stevens, GW

Title:

Axial Dispersion and Mass Transfer of a Pulsed Solvent Extraction Column with Novel Ceramic Internals

Date:

2017-03-22

Citation:

Yi, H., Wang, Y., Smith, K. H., Fei, W. \& Stevens, G. W. (2017). Axial Dispersion and Mass Transfer of a Pulsed Solvent Extraction Column with Novel Ceramic Internals. INDUSTRIAL \& ENGINEERING CHEMISTRY RESEARCH, 56 (11), pp.3049-3058. https://doi.org/10.1021/ acs.iecr.6b04601.

Persistent Link:

http://hdl.handle.net/11343/241471 